\title{
LA INVESTIGACIÓN SOBRE EL HIDRAULISMO ANDALUSÍ Y LOS ASENTAMIENTOS LOCALIZADOS EN EL ALTO MAESTRAZGO (CASTELLÓN) *
}

ÁNGEL POVEDA SÁNCHEZ

Universidad de Alicante

\section{RESUMEN}

Los asentamientos rurales andalusíes incluyen es sus áreas de influencia política zonas de residencia y espacios hidráulicos. Estos últimos, generalmente pequeños y medianos, son el resultado de un diseño previo, llevado a cabo por las comunidades campesinas a partir de la captación del agua y de las características físicas del territorio. En esta investigación, mediante diversas técnicas de trabajo de campo, junto con la documentación escrita y la toponimia, se analizan algunos sistemas hidráulicos localizados en el que fuera distrito administrativo andalusí de Culla (Castellón).

\section{ABSTRACT}

Rural andalusí settlements include both residential and hydraulic zones in their areas of political influence. These hydraulic zones, usually small and medium-sized, are the result of a previous design carried out by the peasant communities and determined by water collecting and the features of the terrain. This paper focusses on some hydraulic systems located in the old andalusí administrative district of Culla in the Spanish province of Castellón. Different field work techniques along with toponyms, documents and other references are used in this research.

* Esta investigación ha contado con una subvención de la DGICYT a través del proyecto PB93-0864-C02-02. En el equipo èncargado del trabajo de campo participaron los profesores A. González Prats y A. Poveda Sánchez, ambos de la Universidad de Alicante, con la colaboración técnica de E. Ruiz Segura, encargada del dibujo de las planimetrías. Agradezco los comentarios y sugerencias de los evaluadores de la Revista de Historia Económica. 


\section{CARACTERÍSTICAS DEL TERRITORIO \\ EN EL QUE SE HA REALIZADO ESTE TRABAJO}

\subsection{El medio físico}

Los asentamientos y espacios hidráulicos que han sido objeto de este estudio están situados en la comarca valenciana del Alto Maestrazgo, provincia de Castellón. El relieve de esta comarca viene determinado por el dominio del Sistema Ibérico, que se manifiesta como una gran plataforma de calizas cretácicas con suaves pliegues, en general noroeste-sureste, con formas estructurales, en parte fosilizadas por depósitos terciarios y exhumadas por la fuerte erosión de los ríos. Donde las capas están más inclinadas aparecen sierras o moles cortadas, como Penyagolosa $(1813 \mathrm{~m})$; pero lo más frecuente son las capas casi horizontales tajadas por ríos y barrancos con un relieve confuso de mesas y muelas ${ }^{1}$.

En el Alto Maestrazgo predominan los suelos pardo calizos, de color oscuro, con un horizonte humífero muy desarrollado, debido al mayor volumen de precipitaciones y a la mayor densidad vegetal en relación con otras comarcas del País Valenciano. Sin embargo, la capacidad de uso de los suelos es muy baja - predominio del litosuelo- como consecuencia de la abrupta topografía, los elevados riesgos de erosión, el reducido espesor efectivo y las acentuadas pendientes ${ }^{2}$. En cuanto al clima, la temperatura media anual es de $11^{\circ} \mathrm{C}$, y la temperatura media en el mes de agosto es de $18^{\circ} \mathrm{C}$; las menos elevadas de cuantas se registran en el País Valenciano. Las precipitaciones oscilan entre los $500 \mathrm{~mm}$ en las zonas más bajas y secas y los $700 \mathrm{~mm}$ en las más lluviosas y altas, situándonos, en consecuencia, en ombroclimas que varían del seco al subhúmedo ${ }^{3}$.

La vegetación potencial de este territorio, de acuerdo con el clima de la zona, corresponde al carrascal meso-supra-mediterráneo - Quercetum rotundifoliae - que en las zonas más elevadas y húmedas se enriquece con robles, transformándose en auténticos robledales -Violo-Quercetum fraginae-. En las zonas más secas y cálidas de los cursos bajos del río Montlleó y de la rambla Carbonera, algunas plantas termófilas, como la rubia - Rubia peregrina subsp. longifolia-, el palmito - Chamaerops bumi-

\footnotetext{
${ }^{1}$ De Terán y Solé Sabarís (1969), p. 333; varios autores (1991), p. 48.

2 Varios autores (1991), pp. 56-59.

${ }^{3}$ Varios autores (1990), p. 489; varios autores (1991), p. 81.
} 
lis - y otras, matizarían los carrascales termo-mediterráneos - Rubio-Quercetum rotundifoliae - ${ }^{4}$.

Los recursos hidráulicos de esta comarca dependen del sistema acuífero del Maestrazgo. Esta unidad hidrogeológica ocupa la parte septentrional del País Valenciano, extendiéndose, además, por las provincias de Tarragona y, especialmente, de Teruel. Está constituida por una extensa paramera carbonatada, en la que los tramos que pueden constituir acuíferos se circunscriben a los niveles permeables de calizas y dolomías del Jurásico y Cretácico y a los detríticos costeros del Cuaternario. La unidad se divide en dos subunidades. La primera corresponde al Maestrazgo propiamente dicho y la segunda a las planas litorales. El Maestrazgo actúa a modo de colector que se vacía al mar a través de estas últimas.

La alimentación de este sistema acuífero se produce exclusivamente de la filtración de agua de lluvia. El caudal de agua acumulado se descarga mediante manantiales, fuentes, extracciones de pozos, salidas a otros sistemas y también por las descargas a los ríos. Las características hidrogeológicas más significativas son la gran profundidad a la que se encuentra el nivel piezométrico y la complicada estructura geológica, que origina compartimentación en bloques. Estos hechos imponen una gran dificultad para la captación del agua 5 .

\subsection{La organización administrativa del territorio}

Dentro del amplio espacio que abarca la comarca del Alto Maestrazgo, se ha elegido un perímetro concreto para llevar a cabo nuestra investigación. Este perímetro viene determinado por los confines del que fuera, durante el período andalusí, bisn - castillo- o territorio fortificado de Culla, que está documentado en las fuentes árabes (Kulya), en 1128, con motivo de una expedición militar realizada por un príncipe almorávide ${ }^{6}$. Cincuenta años después, en un documento sobre la delimitación del obispado de Tortosa, se recoge, entre otros lugares, el distrito castral de Culla ${ }^{7}$.

Sin embargo, no tenemos una noción exacta del territorio que abarcaba el bisn de Culla hasta 1213, fecha en la que Pedro II de Aragón hizo

${ }^{4}$ Varios autores (1990), p. 315; Aguilera y Fabregat (1994), pp. 118-119.

5 Varios autores (1987); varios autores (1990), p. 455; Sanfeliu, Boix y Jordán (1994), pp. 188-189.

'C. Barceló (1994), p. 216; Al-Idrisi (1989), p. 239; Ibn al-'Abbar (1887, 1956).

7 Bazzana, Cressier y Guichard (1988), p. 261; Forcada (1990), p. 12; Guinot (1994), pp. 17-36. 
donación de estas tierras, si eran conquistadas, a la Orden militar del Temple. Según esta descripción, la extensión de este distrito andalusí sería algo superior a los $550 \mathrm{~km}^{2}$ (véase la fig. 1) ${ }^{8}$. El hisn de Culla comprendía los municipios actuales de Vilafranca, Benassal, Culla, Vistabella, Atzeneta, Benafigos, La Torre d'En Besora y Vilar de Canes.

La cabecera administrativa de este distrito la ocupaba la plaza fortificada de Culla - castrum y villa - cuyo nombre identificaba a todo el territorio; y un conjunto de alquerías, castillos y núcleos de población distribuidos de forma dispersa. Esta demarcación territorial responde a las características estructurales propias de los hisn o castillos conocidos y estudiados en otras zonas del levante peninsular ${ }^{9}$. De entre los topónimos documentados, tres se refieren a castillos: Corbó, El Boi y El Castellar (véase la fig. 1). En todos ellos se han encontrado restos de construcciones medievales y cerámica del período andalusí. Además, en el distrito de Culla se pueden identificar tres antropónimos gentilicios - Benafigos, Benassal y Torre de Vinrobí-, y un topónimo tribal: Atzeneta, derivado del nombre de la tribu beréber Zanata.

Aunque no conocemos con precisión la antigüedad de esta organización del poblamiento ${ }^{10}$, las excavaciones arqueológicas que hemos practicado en dos alquerías de la zona nos sitúan en un horizonte temporal que abarca los siglos $\mathrm{x}$ al XIII. La posibilidad prevista de realizar trabajos arqueológicos en el recinto amurallado del municipio de Culla podría facilitar datos relevantes sobre este extremo.

Después de la conquista feudal (1233-1234), el Castell de Culla sufrió una merma en su territorio, efectuada en etapas sucesivas, hasta quedar estabilizado, en 1303, con la venta de este territorio a la Orden del Temple. Los castillos, villas y lugares documentados en esa fecha son los castillos de Culla, de Corbó y de El Boi, además de Vistabella, Benafigos, Atzeneta, El Molinell, la Torre de Vinrobí y Benassal, junto con los lugares llamados de Vilar de Canes y del Castellar (fig. 1) ${ }^{11}$.

De la consulta de la documentación escrita se desprende que solamente en la alquería de El Molinell sobrevivió una comunidad andalusí a la conquista y colonización feudal ${ }^{12}$. Esta comunidad, con unos efectivos redu-

${ }^{8}$ Forcada (1990), pp. 3-34; Miralles (1983), pp. 237-241.

9 Bazzana, Cressier y Guichard (1988), pp. 159-292.

10 Bazzana, Cressier y Guichard (1988), p. 263.

${ }^{11}$ Forcada (1990), pp. 26-32; Forcada (1994), p. 233; Miralles (1983), pp. 237-241.

12 Tenemos previsto publicar, próximamente, un estudio específico sobre el asentamiento y el sistema hidráulico de El Molinell. 


\section{FIGURA 1}

Plano general de los asentamientos y espacios irrigados estudiados
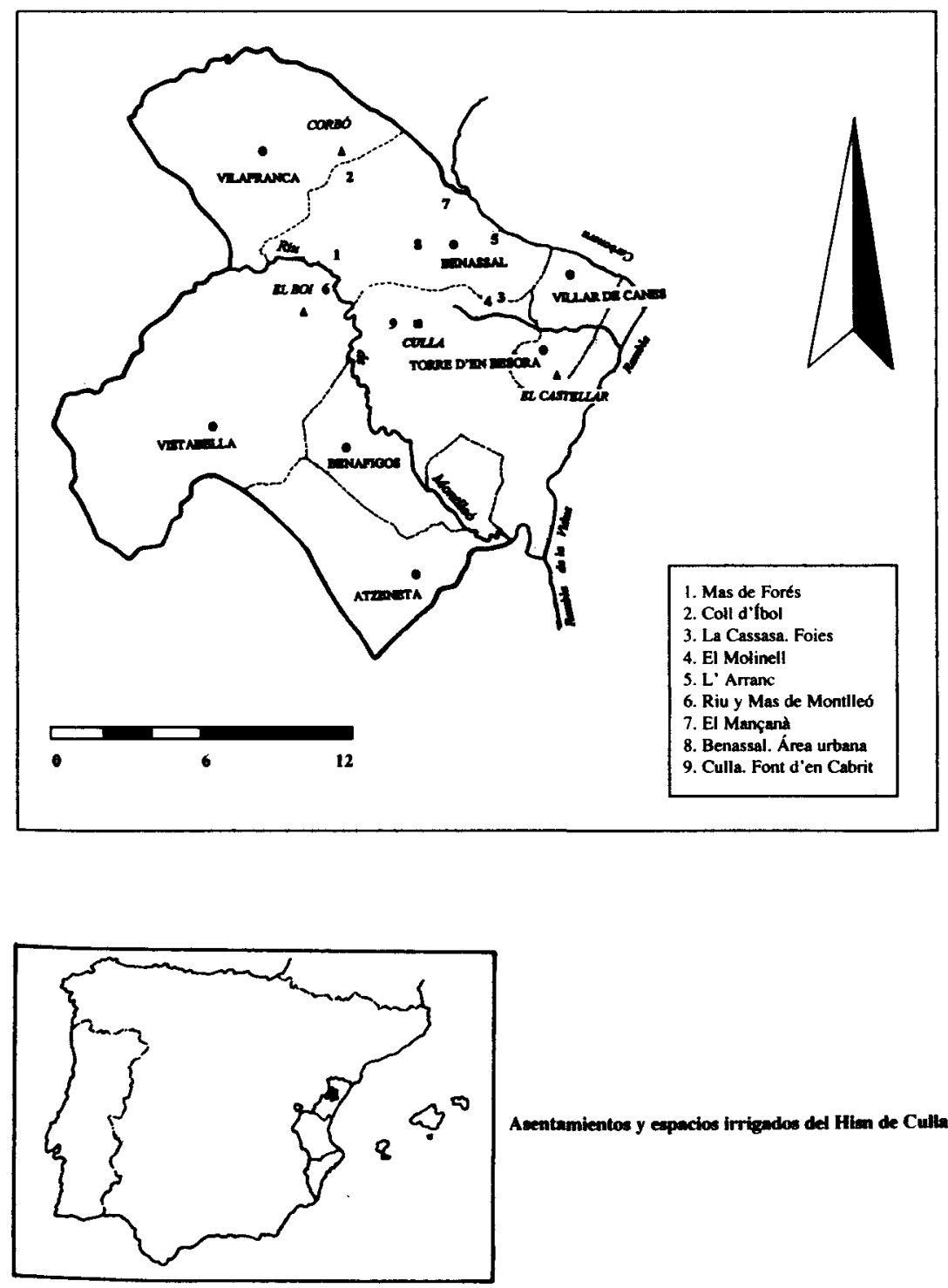

Asentumientos y eapacios irrigados del Hilen de Culla 
cidos y reocupada en parte la alquería por familias cristianas, todavía parece existir a la altura de los años sesenta del siglo XIV. A principios del siglo siguiente El Molinell estaba poblado exclusivamente por campesinos cristianos ${ }^{13}$. La especial dureza de las cargas fiscales que recaían sobre la población musulmana había provocado el abandono definitivo de su antiguo asentamiento.

\section{LOS SISTEMAS HIDRÁULICOS DE ORIGEN ANDALUSÍ ESTUDIADOS}

El programa de investigación planteado para la comarca del Alto Maestrazgo forma parte de un proyecto de mayor alcance, que incluye otras zonas de los extinguidos dominios de al-Ándalus ${ }^{14}$. El propósito de este trabajo es conocer, mediante diversas técnicas de trabajo de campo como la prospección arqueológica e hidráulica y el estudio paralelo de la toponimia y de la información documental, las características y la lógica de funcionamiento de una serie de sistemas vinculados al agua. En el territorio del Castell de Culla se ha recurrido, además, a la excavación arqueológica para obtener una información más completa sobre la composición de los asentamientos y su cronología.

El objetivo esencial consiste en establecer la relación existente entre los espacios irrigados de producción agricola y las zonas de residencia, en cada uno de los asentamientos estudiados. Estos datos nos permiten conocer mejor cómo organizaban las comunidades rurales andalusíes estos espacios, cuáles debieron ser las previsiones que rigieron el tamaño y el diseño de los campos cultivados y, en algunos casos, qué transformaciones sufrieron estos espacios tras la conquista feudal. Cuando el volumen y la calidad de la información lo permitan, los resultados de esta investigación, junto con otras que deberán plantearse en la misma línea, harán posible formular hipótesis acerca del tamaño de las poblaciones de las alquerías de origen árabe o beréber, en relación con los perímetros hidráulicos y las superficies de las zonas de residencia.

En total han sido diez los asentamientos y sus espacios irrigados analizados hasta ahıra en el Castell de Culla, todos ellos ubicados en los términos municipales de Benassal, Culla, y en la parte norte de Vistabella,

13 Guinot (1986), pp. 36, 243, 291.

14 Se trata de un proyecto coordinado entre las universidades Autónoma de Barcelona y Alicante, y dirigido por el profesor Miquel Barceló. 
es decir, en la zona central del perímetro que abarcaba el bisn andalusí (véase la fig. 1). La relación de lugares estudiados es: Mas de Forés, Coll d'Íbol, Foies-La Cassasa, El Molinell, L'Arranc, Riu de Montlleó, El Mançanà, área urbana de Benassal, La Font d'en Cabrit y La Bolicha. En los casos de Benassal (área urbana) y de La Font d'en Cabrit, se ha trabajado sobre espacios irrigados adyacentes a los núcleos de población de Benassal y Culla, respectivamente. El Molinell y el Riu de Montlleó representan sistemas hidráulicos donde se combinan bancales cultivados y molinos harineros, relacionados, en ambas ocasiones, con áreas de residencia de datación andalusí. En el resto de los asentamientos prospectados - Mas de Forés, Coll d'Íbol, Foies-La Cassasa, L'Arranc, El Mançanà y La Bolicha- se ha podido determinar la ubicación precisa del área de residencia andalusí, a través de los restos arqueológicos hallados, así como los espacios irrigados asociados a estas zonas residenciales.

Asimismo, como se ha advertido antes, en los casos de Foies-La Cassasa y de L'Arranc se han realizado sendas campañas arqueológicas de excavación durante los años 1995 y 1996 que han permitido conocer de forma detallada cómo era la estructura de las viviendas que formaban la zona residencial de estas alquerías, las técnicas constructivas empleadas, y la estratigrafía y la datación del material cerámico encontrado. Además, el trabajo de excavación nos ha proporcionado información precisa, particularmente en Foies, sobre la dimensión del perímetro residencial del asentamiento y su posterior reutilización tras la conquista feudal, datada por los cambios observados en las viviendas y en la cerámica ${ }^{15}$.

El estudio de los sistemas hidráulicos que incluyen, además de campos de cultivo, molinos y otros elementos como acequias, balsas, etc., que permiten regar y aprovechar la energía cinética del agua para procurar la moltura de granos y legumbres no es, en esencia, un estudio sobre la tecnología relacionada con el agua. La información que se obtiene mediante el trabajo de campo, a través de la práctica de la arqueología extensiva e hidráulica, no debe considerarse un fin en sí misma. Hacer inventarios completos sobre artefactos hidráulicos, parcelas de cultivo irrigadas, redes de acequias y conjuntos de balsas que sirven para almacenar al agua y regular los caudales, no es tampoco el objetivo último de esta investigación. Estos inventarios, las planimetrías que resultan del trabajo de campo, y la observación de las formas que adquieren los espacios cultivados y los sistemas diseñados

${ }^{15}$ A. González y E. Ruiz están procediendo al inventario de los materiales obtenidos en ambas excavaciones, que será publicado en su totalidad. 
para un aprovechamiento eficiente del agua son necesarios, resultan imprescindibles, pero no constituyen el objeto más profundo de conocimiento planteado.

Este proyecto concreto, del mismo modo que otros propuestos con anterioridad, participan de una finalidad común: aumentar nuestros conocimientos sobre los campesinos andalusíes. No se trata, pues, de «historia de la tecnología», sino de una investigación que se articula en torno a los campesinos, la vinculación de éstos con el territorio, y los medios de que disponen para transformarlo.

En el inicio de esta preocupación por situar a los campesinos en el centro de la inteligibilidad de la sociedad andalusí está, sin duda, la obra de Pierre Guichard. Este autor ${ }^{16}$, en efecto, fue el primero en plantear el problema de la organización social de al-Ándalus como objeto central de su investigación, partiendo de la ruptura que significó la conquista musulmana de la Península ${ }^{17}$. M. Barceló ${ }^{18}$ ya advirtió que es impensable una historia de al-Ándalus sin campesinos, a pesar del empeño de algunos autores en concebir a aquella sociedad medieval como una sociedad eminentemente urbana. Los argumentos de Barceló ${ }^{19}$ son consistentes: los campesinos son el sujeto fundamental de la fiscalidad andalusí ya que, según sus cálculos, la tributación de esta fracción social representaba, a mediados del siglo $\mathrm{X}$, entre el 85 y el 90 por 100 de los ingresos del Estado por todos los conceptos.

La investigación de P. Guichard sobre el levante peninsular le ha permitido elaborar una propuesta sólida acerca de la lógica de funcionamiento que se encontraba en la base de aquella sociedad: los inmigrantes mayoritariamente beréberes, en relación con los menos numerosos de origen oriental, extendieron y conservaron durante un dilatado período las organizaciones tribales y clánicas en esta extensa región andalusí. Una sociedad así estructurada, con un fuerte peso de la familia política, impidió el desarrollo de relaciones de producción feudales y, en consecuencia, ocluyó la posibilidad de dominar hombres.

El otro polo de aquella organización social era el Estado, que se nutre esencialmente de la producción campesina. Precisamente por esta razón, el Estado impide también la aparición de señores de renta que, de existir, le disputarían el flujo tributario, cuyo control es el sustento del poder polí-

\footnotetext{
16 Guichard (1976).

17 Poveda (en prensa).

${ }_{18}$ Barceló (1992a), pp. 457-462.

19 Barceló (1992b), pp. 245-246.
} 
tico que representa y ejerce el Estado andalusí, cualquiera que sea su dimen$\operatorname{sión}^{20}$. M. Acién indicó oportunamente que para procurar la consolidación del Estado Omeya fue de gran trascendencia la derrota de los Banu Hafsun, grupo que representaba a los últimos señores de renta, de origen indígena, que dominaban campesinos ${ }^{21}$.

Las comunidades campesinas deciden, pues, autónomamente, cómo organizar los asentamientos y qué producir, además de poder bloquear, con la ayuda del Estado, la aparición de señores de renta ${ }^{22}$. El ejercicio de esta capacidad de decisión es el resultado de la sólida cohesión social que fortalece a los clanes y tribus frente al poder exterior. El Estado se acepta sólo en un sentido instrumental: como institución que, por una coincidencia de intereses, contribuye a sostener la autonomía campesina. Pero, en realidad, estas comunidades desconfían del Estado, rechazan un poder político que, eventualmente, puede excederse en su presión tributaria y, de este modo, socavar la libertad campesina y su propia capacidad de organizar la producción ${ }^{23}$.

Esta «prevención» de la comunidades rurales en relación con el Estado se ha podido comprobar en Mallorca, donde la mayoría de los asentamientos tribales y clánicos identificados, que en un 85 por 100 son de origen beréber, se concentraban en las zonas más alejadas de la madina, centro del poder estatal ${ }^{24}$. Además, tanto mi investigación sobre Mallorca, como la realizada posteriormente por $\mathrm{H}$. Kirchner ${ }^{25}$, parecen apuntar claramente a la vigencia de los principios genealógicos en esta isla en vísperas de la conquista feudal.

La tecnología hidráulica que podemos reconocer a través de la prospección arqueológica es consecuencia del trabajo de los grupos campesinos, organizados genealógicamente, cuyos conocimientos les permiten difundir y adaptar dicha tecnología al territorio en el que se asientan. Las decisiones que adoptan en el seno de la comunidad campesina implican qué producir y cómo hacerlo, de modo que los procesos de trabajo se conciben en función de un objetivo básico: asegurar la subsistencia del grupo, al margen de

${ }^{20}$ Barceló (1992b), p. 246, señala al respecto que «lo que no hay es la posibilidad de establecer dominios legales y estables sobre el trabajo de otro... El Estado depende, justamente, de que eso no suceda».

${ }^{21}$ Acién (1984a), vol. I, pp. 21-45; Acién (1984b), vol. II, pp. 469-510; Acién (1989), vol. I, pp. 137-150.

\footnotetext{
22 Barceló (1992c), pp. 63-73.

${ }^{23}$ Barceló (1995), pp. 25-38.

24 Poveda (1987), pp. 275-277; Poveda (1992), p. 7.

${ }^{25}$ Kirchner (1997), pp. 48-54.
} 
cualquier intromisión de un poder externo. Si la opción preferente de los campesinos es la agricultura irrigada, tal opción es el resultado coherente de producir un tipo de cultígenos que sean difícilmente aprehensibles, imposibles de acumular y, en consecuencia, «adversos a la posibilidad de surgimiento de señores de renta» ${ }^{26}$.

Así, mientras la exigencia de la renta feudal en forma de productos móviles, almacenables y comercializables, como cereales, aceite, vino o ganado, determina la producción campesina, de manera que la capacidad de elección de éstos es escasa, las comunidades rurales andalusíes, al producir frutas y verduras, no sólo deciden en qué consiste parte de su dieta, sino también cómo dificultar la expropiación de su trabajo en forma de excedentes.

El conjunto de elementos relacionados entre sí que forman los sistemas hidráulicos cobran sentido a partir de la comprensión del motivo de esta opción campesina. La tecnología hidráulica desarrollada y aplicada por estas comunidades forma parte de sus procesos de trabajo, tanto en su diseño y construcción inicial como en su mantenimiento, y constituye el instrumento adecuado para dar respuesta a un doble objetivo esencial: procurar la producción y reproducción del grupo campesino y evitar la existencia de señores de renta, que pudieran surgir en el seno de la propia comunidad o procedentes de una autoridad exterior. El pago fiscal exigido por el Estado musulmán —sultán - es el único flujo de excedente que se escapa, inevitablemente, del control campesino. Pero estos pagos, salvo en momentos de turbulencias políticas que pudieran quebrantar la legalidad estatal, no ponían en peligro la sobrevivencia campesina ${ }^{27}$.

El Estado Omeya, a mediados del siglo $\mathrm{x}$, logró establecer un aparato fiscal suficientemente eficaz, cuyo instrumento fundamental era la acuñación de moneda en régimen de monopolio. $\mathrm{Y}$ aunque ésta no era el único medio recaudatorio, ya que también se recaudaba mediante tributos en especie y pagos por aduanas, la moneda era la herramienta más sólida de relación entre el Estado y sus súbditos. En este sentido, parece evidente que las comunidades campesinas estaban forzadas a adquirir moneda para satisfacer la exigencia fiscal. Los procedimientos de esta adquisición todavía no se conocen, si bien sabemos de la existencia de mercados rurales y artesanales que formaban parte del circuito de intercambios de moneda.

${ }^{26}$ Barceló (1989), p. XXXVII.

27 Como ha señalado M. Barceló (1996), p. 45, «la riqueza, en principio, del sultan se debía más al carácter centralizado y monopolista, por así decirlo, de la recaudación del excedente que a la magnitud de éste». Sobre la organización de la fiscalidad andalusí puede consultarse también al mismo autor (1984-1985), pp. 45-72, y (1992d), pp. 15-23. 
No obstante, creemos que la intervención del Estado estuvo siempre limitada y nunca pudo orientar al conjunto de la producción campesina, excepción hecha de aquella pequeña proporción necesaria para cubrir la exacción fiscal en moneda. El Estado andalusí debió resignarse a una función exterior, contenida por la cohesión social de las comunidades campesinas, que sólo se vieron obligadas a ceder, muy levemente, parte de su autonomía.

La introducción de nuevos cultivos vinculados a la agricultura irrigada tuvo una gran importancia, tanto por su efecto sobre la dieta como por la posibilidad de hacer más intensivo el trabajo mediante cultivos de verano. Además, la incorporación de cultivos como el algodón y la caña de azúcar crearon, en algunas zonas de la Península y en Baleares, espacios de especialización productiva dirigidos a una ulterior transformación industrial. Casi todos los cultivos de cuya existencia tenemos hoy información ${ }^{28}$ estaban ya bien aclimatados y difundidos por el Magreb y por al-Ándalus en el siglo $\mathrm{x}^{29}$.

Las cuestiones hasta aquí consideradas requieren un tratamiento metodológico innovador que proporcione respuestas de calidad, adecuadas al objeto nuclear de esta investigación: la estructura social campesina y la organización de sus procesos de trabajo. En este sentido, las posibilidades analíticas de la arqueología se han revelado consistentes y capaces de sustentar una línea de trabajo científico acorde con los objetivos propuestos.

$\mathrm{La}$ arqueología extensiva es la aplicación metodológica que más y mejores resultados está proporcionando en el estudio de los asentamientos islámicos ${ }^{30}$. En la práctica, el trabajo de campo debe centrarse en determinar las zonas de residencia y su relación con los campos de cultivo, y en reconocer los perímetros irrigados y su morfología, para, de este modo, obtener información sobre los procesos de trabajo campesinos y la lógica social que los sustentan ${ }^{31}$. Esta forma de proceder ha de integrar asimismo la documentación escrita, mediante el trabajo paralelo en los archivos que, unido al estudio toponímico, facilitan la identificación de los asentamientos $y$, en determinadas ocasiones, también su evolución ${ }^{32}$.

28 Watson (1983).

29 Barceló (1996), pp. 41-47.

${ }^{30}$ Según M. Barceló (1988), p. 195, la arqueología extensiva «implica la movilización de toda la información, incluida la escrita, para identificar, relacionar y entender todas las trazas de los asentamientos desaparecidos y de los entornos por ellos producidos, también desaparecidos».

${ }_{31}$ Sobre este asunto véase también Barceló (1992b), pp. 242-246.

32 Es posible estudiar la evolución de una zona de riego cuando la documentación de archivo es lo suficientemente rica en cuanto a su continuidad temporal. 
Los textos árabes, sesgados generalmente por la óptica urbana, son poco explícitos para examinar la esfera rural de la historia andalusí. En ellos se pueden encontrar referencias a las vegas de los grandes ríos peninsulares, a sus sistemas de riego y a los artefactos hidráulicos que allí se habían construido. Sobre la pequeña y mediana hidráulica, la ausencia de documentación andalusí es absoluta. Por ello, la documentación feudal, generada inmediatamente después de las conquistas, se torna extremadamente útil, ya que facilita el acopio de datos sobre la infraestructura material que sustentaba a la sociedad vencida y expropiada por efecto de la violencia feudal ${ }^{33}$.

La modalidad arqueológica denominada hidráulica empezó a tener consistencia después de las primeras investigaciones llevadas a cabo en Mallorca y en Guajar Faragüit (Granada), en la segunda mitad de los años ochenta ${ }^{34}$. La puesta a punto del método y su aplicación práctica se ha concretado en los estudios posteriores realizados por $\mathrm{H}$. Kirchner sobre un conjunto de valles mallorquines ${ }^{35}$, de $C$. Navarro sobre Liétor y Letur (Albacete), de $M$. Barceló y su equipo en relación con Ibiza ${ }^{36}$, y de A. González y A. Poveda sobre el Alto Maestrazgo ${ }^{37}$.

El trabajo de campo y los estudios comparados llevados a cabo hasta ahora han hecho posible establecer unos principios generales de la arqueología hidráulica que parten de la exigencia de la gravedad como hecho fundacional de toda hidráulica. Así, se ha observado que los sistemas hidráulicos disponen de una línea de rigidez, determinada por la acequia principal, que limita las posibilidades de modificación de estos sistemas, y hace que los mismos sean estables, incluso, hasta la actualidad. Por esta razón, las ampliaciones o modificaciones en los sistemas hidráulicos se pueden reconocer y distinguir en relación con el diseño original. En todos los casos prospectados, la zona de residencia del grupo campesino se localiza fuera del espacio irrigado, por encima de la línea de rigidez. Esta línea define

${ }^{33}$ La bondad de la documentación feudal escrita en fechas cercanas a la conquista ha quedado plenamente demostrada en los trabajos realizados sobre Mallorca durante el período andalusí. A este respecto pueden verse las aportaciones de Poveda (1987), pp. 159-193; Poveda (1992), pp. 5-11; Poveda (1995), pp. 1061-1067; y de Kirchner (1996), pp. 279-316; Kirchner (1997), pp. 29-32.

34 Barceló et al. (en prensa).

${ }^{35}$ Kirchner (1994a), pp. 517-523; Kirchner (1994b), pp. 313-336; Kirchner (1995b), pp. 351-359; Kirchner (1997).

36 Barceló et al. (1995), pp. 455-463; Argemí et al. (1997), pp. 37-51.

${ }^{37}$ González y Poveda (en prensa); Poveda (1997), pp. 13-29. 
el diseño del sistema, y la articulación de todos los elementos que lo forman ${ }^{38}$.

La relación entre los espacios residencial e irrigado no es solamente funcional, sino que entre ambos se puede establecer un principio de congruencia, derivado de la observación consistente en que el área irrigada es el resultado de un diseño inicial, el cual, a su vez, está en función de las estimaciones que hace el grupo campesino de su horizonte de subsistencia. La coherencia se establece, pues, entre el tamaño del espacio hidráulico y el tamaño poblacional ${ }^{39}$.

Los asentamientos estudiados en el Castell de Culla contienen en sus territorios de influencia política zonas de riego pequeñas que, sólo en algunas ocasiones, son algo mayores de una hectárea, vinculadas a áreas residenciales igualmente reducidas. Los casos de áreas de riego mayores o, en ocasiones, un mayor número de bancales irrigados próximos entre sí, se registran en las proximidades de los núcleos de población más concentrados como Culla y Benassal.

Según su ubicación topográfica, los sistemas hidráulicos se pueden clasificar en sistemas de fondo de valle; de terrazas con captación a media ladera; y sistemas de vertiente. Los primeros son aquellos que se construyen en fondos de valle desboscados y acondicionados para el riego a partir, generalmente, de una sola acequia, desde la cual se riega directamente mediante partidores regularmente distribuidos. Cuando el caudal de la captación es suficiente, se construyen molinos que son situados en la misma acequia ${ }^{40}$. En el Castell de Culla se pueden adscribir a este modelo EI Molinell, el Riu de Montlleó (fig. 2), y la parte del sistema de la Font d'en Cabrit directamente vinculada al aprovechamiento hídrico del lecho del torrente (véase la fig. 3).

El sistema de terrazas con captación a media ladera es el que resulta de la construcción de un conjunto de bancales superpuestos y escalonados en una pendiente natural, siguiendo las curvas de nivel, de modo que ésta queda modificada artificialmente, «asegura la contención del terreno

${ }^{38}$ Barceló (1988), pp. 195-274; Barceló (1989), vol. I, pp. XV-XI XI; Kirchner y Navarro (1993), pp. 121-150.

39 Barceló (1995), pp. 25-38.

40 M. Barceló (1995), p. 28 , indica que en estos casos el aterrazamiento es mínimo y está «condicionado por el desnivel del propio valle y las parcelas de cultivo, alargadas y en forma de huso, se adaptan al relieve y a la sinuosidad del torrente, a menudo canalizado para protegerlas». La situación de los molinos encima de la acequia principal «responde a la estrategia de recuperar el agua utilizada por éstos». No obstante, antes de cada molino se practica una apertura que permite desviar el agua cuando están fuera de servicio. 


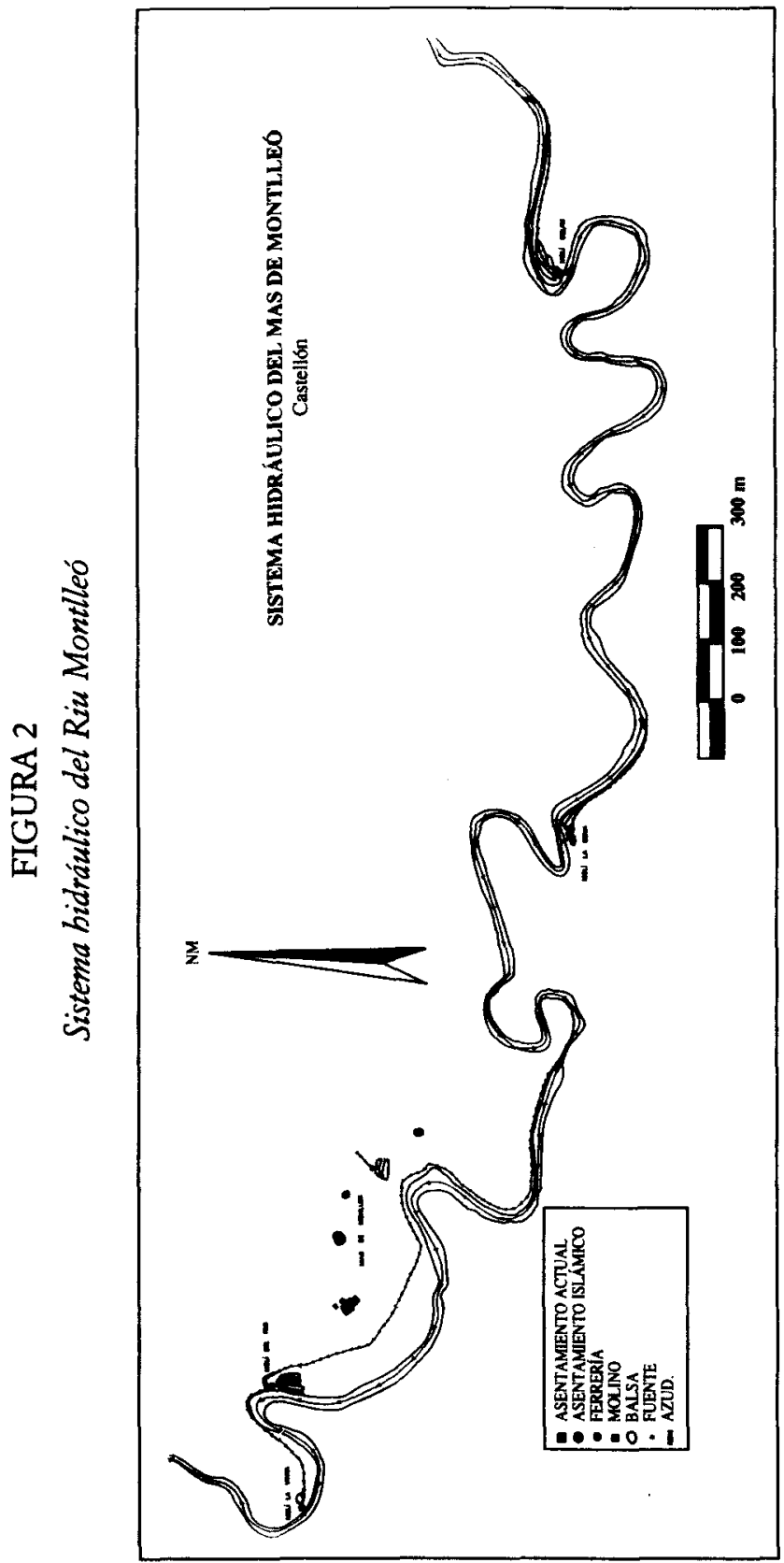


y detiene el efecto de la erosión provocado por las lluvias torrenciales» ${ }^{41}$. $\mathrm{La}$ investigación hecha sobre el territorio de Culla ha desvelado que los espacios irrigados del Mas de Forés, Coll d'Íbol, L'Arranc, El Mançanà, la zona de riego dependiente del débito de la Font d'en Cabrit (fig. 3) $y$, dentro del área urbana de Benassal, los bancales irrigados conocidos como Els Hortassos, responden todos ellos a este modelo.

Finalmente, los sistemas de vertiente se levantan en zonas de pendiente suave, a partir de una captación realizada igualmente en el fondo de valle que permite el acondicionamiento de una de las vertientes para el riego, mediante un cierto aterrazamiento. Estos sistemas se localizan en valles abiertos $^{42}$. En la prospección realizada hasta ahora en el Castell de Culla no se ha registrado ningún asentamiento que disponga de un área regada de estas características.

En el entorno de Benassal hemos encontrado espacios irrigados preferentemente asociados a norias de sangre. Éstas riegan pequeñas parcelas que oscilan entre las $0,053 \mathrm{ha}$, la más pequeña, y $0,38 \mathrm{ha}$, la más grande, siendo las más habituales de 0,15 a 0,20 ha. En total se han prospectado y levantado planimetrías de 16 perímetros de riego, que representan 1,90 ha. En Mallorca ha sido estudiado también un campo de norias en el término municipal de Felanitx ${ }^{43}$, relacionado con un asentamiento del clan beréber de los Banu Farda. Tanto las parcelas de esta zona de riego como las de Benassal están formadas por una noria, una alberca de almacenamiento y regulación del débito y una pequeña superficie regada que, en el caso de Felanitx, tampoco suele superar la media hectárea. En ambos lugares se ha observado que los espacios regados mediante noria siguen un patrón muy regular, salvo pequeñas diferencias poco significativas ${ }^{44}$.

Como se ha indicado antes, las zonas irrigadas que hemos estudiado en el Castell de Culla son de dimensiones reducidas. En Forés se registran 0,14 ha, en el Coll d'Íbol 0,15 ha, en L'Arranc 0,07 ha, en el Mas de Montlleó 0,17 ha, en el Riu de Montlleó, las parcelas asociadas a los molinos -excepción hecha del Molí La Vinya, cuyos bancales no se han podido reconstruir por estar totalmente arruinados- representan 1,1 ha (véase la fig. 2); en el Mançanà 0,34 ha, en Els Hortassos 0,21 ha, en El Molinell

${ }^{41}$ Argemi et al. (1995), p.183.

42 Barceló (1995), p. 30.

${ }^{43}$ Barceló y Kirchner (1995), pp. 63-67.

${ }^{44} \mathrm{La}$ principal diferencia estriba en que en Benassal suele haber una acequia que conduce el agua desde la alberca hasta la parcela, mientras que en Felanitx se riega directamente desde la balsa. 


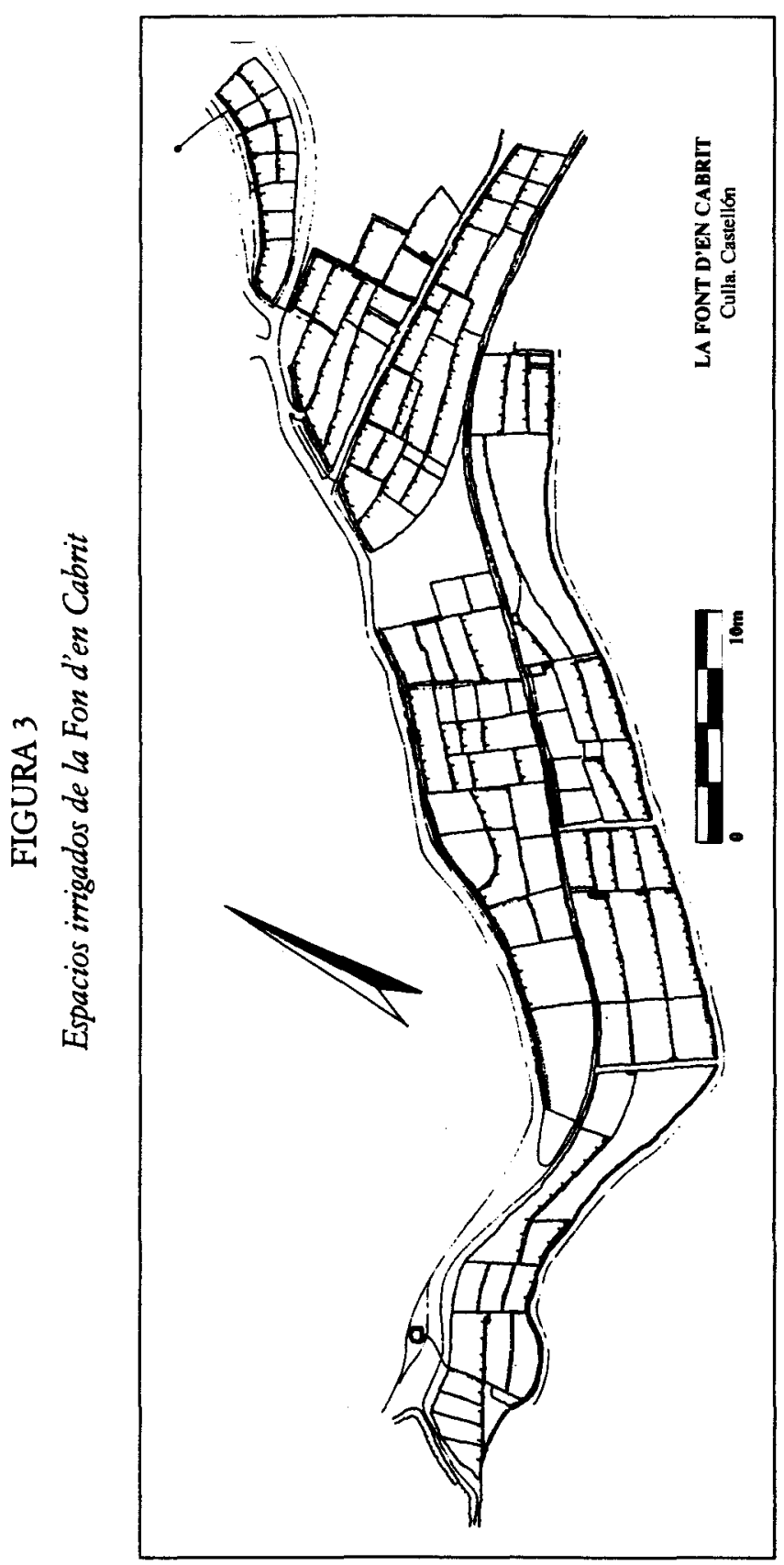


0,4 ha, y en la Font d'en Cabrit 0,35 ha. En este último caso, además, hay un conjunto de parcelas construidas en el fondo del barranco, regadas por capilaridad con el agua del nivel freático, que representan 0,9 ha (fig. 3). Pero, según nuestro análisis, éstas forman parte de un sistema distinto y posterior al diseñado para aprovechar el agua que mana de la Font d'en Cabrit.

En términos comparativos, estos espacios son, generalmente, más pequeños que los conocidos hasta ahora en Mallorca ${ }^{45}$ o en Ibiza ${ }^{46}$. En relación con los descritos en Liétor (Albacete) son también reducidos, ya que en aquellos asentamientos las dimensiones oscilan entre las 2,8 ha y las $4,8 \mathrm{ha}^{47}$. Sin embargo, sí guardan semejanza con la huerta de Margalida (Alicante), cuya área irrigada es de $0,38 \mathrm{ha}^{48}$.

En El Molinell y en el Riu de Montlleó se ha trabajado sobre sendos sistemas hidráulicos que incluyen, junto a los molinos y a las balsas necesarias para su abastecimiento, parcelas irrigadas y otros elementos que hacen posible el funcionamiento de estos sistemas. El Molinell ${ }^{49}$ consta de seis molinos harineros, situados en el torrente del mismo nombre, que se extiende entre los términos municipales de Culla y Torre d'En Besora (fig. 1). Previamente a cada molino hay una balsa con la función de acumular el agua ya que, ante el escaso caudal de las fuentes que abastecen el sistema, es el único modo de obtener una presión uniforme y continuada para mover la rueda del molino. El sistema utilizado en la mayoría de los casos para conducir el agua desde la balsa al rodezno es la rampa cubierta. Solamente en dos molinos se ha recurrido al cubo vertical de forma cilíndrica. Todos los ingenios localizados en El Molinell son de rueda horizontal, con transmisión directa de la rotación a la muela mediante un eje vertical.

Las terrazas de cultivo están asociadas a cada uno de los molinos, situadas previamente a éstos, y regadas con el agua conducida por la acequia principal, que se deriva para ello a través de partidores. Los molinos están todos construidos encima de la acequia, de modo que el agua utilizada

45 Alli, según Kirchner (en prensa), oscilan entre 1 y 2 ha.

${ }^{46}$ En Beniformiga las dimensiones de la zona de riego pueden alcanzar las 2,63 ha; y en Buscastell, también en Ibiza, llegan a 2,46 ha. Estos ejemplos pueden consultarse en Argemí et al. (1997), pp. 37-51.

${ }^{47}$ Navarro (1996), pp. 177-189.

48 Vea (1996), pp. 203-213.

$49 \mathrm{El}$ trabajo de campo básico sobre este asentamiento fue realizado por $\mathrm{H}$. Kirchner y M. Argemí, y completado después por A. González y A. Poveda, más recientemente, junto con el examen de la documentación disponible. Próximamente publicaremos los resultados obtenidos del estudio de este sistema. 
para su movimiento es recuperada a la salida y reconducida nuevamente. Cada molino cierra un bloque de parcelas que morfológicamente permite organizar la distribución del agua.

El sistema del Riu de Montlleó ${ }^{50}$ se localiza en el límite entre los términos municipales de Vilafranca, Vistabella y Benassal (fig. 1), y ocupa, como El Molinell, un fondo de valle. En este caso, son cuatro molinos, con espacios irrigados asociados. La estructura y funcionamiento de este sistema difiere, parcialmente, de la observada en el río Molinell ${ }^{51}$. Aquí, todos los molinos son de rueda horizontal y utilizan la rampa cubierta como forma de impulsión del rodezno. Las terrazas irrigadas se localizan siempre previamente a los molinos, dándose prioridad al riego sobre la moltura. También en el Riu de Montlleó los molinos se levantan sobre la acequia principal y cierran los bloques de parcelas (véase la fig. 2).

Otros sistemas idénticos a los aquí citados han sido descritos también en la Serra d'Espadà (Castellón) ${ }^{52}$. Todos ellos, adscritos al período andalusí, comparten la característica común de situar los molinos de manera que no entorpezcan el riego, y de tal forma que la moltura no suponga la pérdida del agua utilizada. La instalación de los molinos encima de la acequia principal obedece a esta preferencia del riego sobre el funcionamiento del molino. Tras la conquista feudal, parece que hubo un cambio de preferencia, ya que el molino cumplía una función de monopolio señorial. Es posible reconocer esta mudanza mediante el examen detallado de la estructura de los sistemas hidráulicos hoy conservados, además de poder constatarse, en algunos casos, mediante la documentación escrita ${ }^{53}$. La localización de molinos encima de la acequia principal se ha comprobado, asimismo, en Mallorca y en Ibiza ${ }^{54}$.

so Un análisis más extenso y pormenorizado puede verse en Poveda (1997), pp. 19-24.

${ }^{51}$ Este asunto puede consultarse en González y Poveda (en prensa).

52 Selma (1989), vol. II, pp. 713-736; Selma (1991), pp. 65-100.

53 A este respecto $S$. Selma (1991), pp. 72.73, señala que la congruencia de un espacio hidráulico en el que existen molinos y zonas de riego estriba en que los molinos ocupen un emplazamiento tal que no dificulten la distribución del agua para el riego. Por el contrario, cuando el molino se sitúa en un lugar que le proporciona preferencia sobre el agua, se generan zonas marginales de riego o pérdidas de agua, y puede considerarse que la instalación del molino ha sido posterior al diseño del sistema. A. Furió y L. P. Martínez Sanmartín (1994), pp. 578-586, han estudiado los azudes y molinos del río Júcar, y tambien la transformación social introducida por el establecimiento del régimen feudal en esa demarcación.

54 Para Mallorca pueden verse los casos de Coanegra en Kirchner (1995b), pp. 351-359; Bunyola en Kirchner (1996), pp. 279-316; Alaró en Riera y Soberats (1992), pp. 61-73, y en Kirchner (1997), pp. 271-328; Alfabia en Kirchner (1997), pp. 205-217; Sèquia de 
En cuanto a las características técnicas de los molinos, ya he indicado que todos los estudiados hasta ahora en el distrito del Castell de Culla son de rueda horizontal y, generalmente 55 , de un solo rodezno. La forma de conducir el agua desde la balsa hasta la rueda de palas o álabes es, en El Molinell, en cuatro ocasiones la rampa cubierta y, en otras dos, el cubo vertical de forma cilíndrica. En el Riu de Montlleó todos los molinos disponen de rampa cubierta. El principio en el que se basa el cubo vertical consiste en crear una columna de agua constante en un depósito cilíndrico en cuya salida, más estrecha que el diámetro del cubo, el agua sale con fuerza para golpear en los álabes de la rueda y hacerla girar. La rampa cubierta o, también, cubo inclinado, se fundamenta en que al constituir un depósito de agua con desnivel, se obtiene presión y, al mismo tiempo, la inclinación del depósito le confiere al agua también velocidad ${ }^{56}$. Los molinos de cubo vertical han sido documentados en distintos lugares de al-Ándalus ${ }^{57}$, mientras que los que emplean rampa cubierta han sido descritos, asimismo, en otras zonas de Castellón ${ }^{58}$.

$\mathrm{El}$ área de residencia vinculada a los sistemas hidráulicos prospectados en el bisn o Castell de Culla se encuentra siempre situada por encima de la línea de rigidez del sistema o acequia principal, de modo que su localización no interfiere ni en el desarrollo ni en el funcionamiento del sistema. La simple observación previa de las fotografías aéreas y, posteriormente, la prospección sobre el terreno, permiten establecer con claridad la relación existente entre las zonas de residencia y los campos de cultivo. En el Mas de Forés, L’Arranc y El Mançanà la relación espacial es inme-

la Vila de Palma de Mallorca en Fontanals (1984) y Carbonero (1992), pp. 95-189; Sóller en Carbonero (1986), pp. 137-155; Carbonero (1992), pp. 260-280; y Artà en Argemí (1996), pp. 259-271. Para Ibiza pueden consultarse las descripciones de los sistemas hidráulicos de Buscastell en Barceló et al. (1995), pp. 455-463, y en Argemí et al. (1997), pp. 37-51.

55 El Moli del Pas de Vistabella, que forma parte del sistema hidráulico del Riu Montlleó (fig. 2), dispone de dos ruedas de álabes en su cárcavo: una para hacer girar la piedra volandera, y la otra para accionar la maquinaria utilizada para la limpieza del grano. A este respecto véase Poveda (1997), p. 22.

56 Sobre las formas alternativas de conducir el agua al rodezno puede consultarse a Argemí et al. (1995), pp. 172-173.

57 Para Mallorca pueden verse los trabajos de Carbonero (1986), pp. 137-155; Carbonero (1992), pp. 152-168; Kirchner et al. (1986), pp. 77-86; Kirchner (1997), pp. 108-112, 174-178, 289-291; Argemí (1996), pp. 259-271; Barceló et al. (en prensa). Para Ibiza véase Barceló (coord.) (1997). Para Alicante puede consultarse a Gregori et al. (1985). Para Málaga, Fernández (1982), pp. 208-238. Y, en relación con la Sierra de Albacete, entre otros lugares de la Península, consúltese a Navarro (1989), 97-110; Navarro (1996), pp. 177-189.

58 Selma (1989), pp. 713-736; Selma (1991), 65-100; Selma (1993). 
diata: justo encima de la acequia principal y de la captación del agua se halla el lugar de residencia, reconocido por los restos arqueológicos que ofrecen ${ }^{59}$.

En Foies-La Cassasa, el grupo de casas andalusíes excavado, que ocupa una superficie de 0,49 ha, con un espacio habitable de 0,35 ha, se sitúa en una pequeña loma, debajo de la cual, a una corta distancia, encontramos la noria y los bancales irrigados correspondientes. En el Coll d'íbol, la zona de residencia andalusí se localiza a una distancia aproximada de 1,5 $\mathrm{km}$ de las parcelas de cultivo, siguiendo el camino que comunica ambos espacios. En El Molinell, el área de residencia, formada actualmente por una quincena de casas, se sitúa entre la Fontassa —que es una de las fuentes que alimenta el sistema-y el primer molino, en una cota superior a la acequia principal. Según la documentación consultada, en 1320, cuando El Molinell estaba habitado todavía por una comunidad mudéjar, había en ese lugar 25 casas y, según nuestros cálculos, una superficie irrigada de 0,42 ha.

En el Riu y Mas de Montlleó, la alquería islámica se encuentra entre los molinos de La Cova y de El Pas (véase la fig. 2), más arriba de la acequia que conduce el agua a los molinos. La zona de residencia de la alquería está a unos $150 \mathrm{~m}$ de los bancales regados, encima de la fuente que bonifica a estas parcelas. Los bancales regados que todavia hoy podemos reconocer junto a tres de los molinos representan 1,1 ha.

Finalmente, la Font d'en Cabrit y otros posibles aprovechamientos del barranco de Cullola, se asocian de forma evidente al municipio de Culla ya que, en realidad, es el único espacio que reúne las condiciones necesarias para ser convertido en una zona de riego abastecedora del núcleo fortificado. Del mismo modo sucede con el campo de norias y otros sistemas de riego relacionados con el pueblo de Benassal, al que me he referido antes.

La relación espacial entre las zonas de residencia y los espacios irrigados permite concluir, en los casos estudiados en el Castell de Culla, y en otros ejemplos de Mallorca, Ibiza y Albacete, que el sistema hidráulico fue diseñado por grupos andalusíes asentados en su entorno. Asimismo, podemos establecer que la selección del área residencial se produce posteriormente a la decisión sobre dónde construir el espacio irrigado; y que la hipótesis

59 En el Mas de Forés se ha localizado también un campo de silos, excavados en la roca base. De igual modo, en el asentamiento andalusí de Felanitx (Mallorca) se ha documentado un campo de silos relacionado con el perímetro residencial de la alquería, según Kirchner (en prensa). 
de congruencia entre el tamaño y la función de los campos de cultivo y las zonas residenciales, a falta del estudio de un mayor número de casos, parece contrastarse ${ }^{60}$.

En este sentido, los inventarios sobre sistemas de alquerías, con aprovechamiento común de espacios irrigados, y de alquerías aisladas, con perímetros hidráulicos individualizados, que se puedan llevar a cabo en distintas regiones de al-Ándalus, facilitarán la elaboración de estimaciones acerca del tamaño de la población campesina andalusí. También, la información sobre el número de casas construidas en las áreas de residencia de los asentamientos, junto con el tamaño medio de las viviendas, obtenido a partir de los trabajos de excavación realizados en algunas alquerías -como hemos podido comprobar en el asentamiento excavado de Foies-La Cassasa-, pueden contribuir a la elaboración de dichas estimaciones. Aunque, en el estado actual de la investigación, no conocemos cuál era la célula familiar que habitaba cada casa en al-Ándalus y, en consecuencia, no podemos establecer todavía un índice de habitantes por vivienda ${ }^{61}$.

La rigidez de los espacios hidráulicos, derivada de la lógica organizativa que ha desvelado la arqueología hidráulica, provoca que la emigración sea la respuesta de los grupos campesinos cuando se produce un crecimiento demográfico. Esta posibilidad se concreta, en las sociedades estructuradas a partir de principios genealógicos, en la alternativa segmentaria ${ }^{62}$; dicho de otro modo: la segmentación o fraccionamiento del grupo tribal o clánico ante el aumento poblacional. Sobre esta forma de proceder se puede obtener información de calidad mediante la identificación de topónimos reduplicados, que expresa, a través de un mismo nombre identificado en diferentes emplazamientos, la existencia de dos o más asentamientos del mismo grupo de parentesco ${ }^{63}$.

En el territorio del Castell de Culla se ha identificado un asentamiento tribal del grupo beréber Zanata, que en la actualidad da nombre al municipio Atzeneta. Seguramente éste es otro ejemplo de segmentación, ya que encontramos otros topónimos derivados del nombre Zanata también en Alicante - L'Atzeneta y L'Atzaneta-, en Valencia - L'Atzaneta d'Albai-

${ }^{60}$ Barceló (coord.) (1997); Barceló (1992c), pp. 63-73; Kirchner (en prensa).

${ }^{61}$ Barceló y Kirchner (1995), p. 33.

62 Véase al respecto a Barceló (1989), pp. XV-XIXI; Barceló (1995), pp. 25-38.

${ }^{63}$ Algunas investigaciones llevadas a cabo o en curso de realización tienden a confirmar la hipótesis de la segmentación del grupo inicial. En relación con este asunto se puede consultar a Barceló (1989), pp. XV-XLXI; Navarro (1995), pp. 365-378, y Vea (1996), pp. 203-213. 
$\mathrm{da}$ - o, entre otros lugares de los extintos dominios de al-Ándalus, en Mallorca - las alquerías Atzenet y Azenet- ${ }^{64}$, que también podrían ser objeto de estudio en cuanto a su vinculación con espacios irrigados y zonas de residencia.

\section{CONSIDERACIONES FINALES}

El conocimiento de los aspectos físicos de la comarca valenciana del Alto Maestrazgo, en la que se ubica el territorio estudiado del bisn de Culla, permite entender mejor las formas de adaptación a ese medio de las comunidades campesinas allí asentadas, así como las actividades económicas por ellas desarrolladas.

Los espacios de riego de los asentamientos prospectados se han podido analizar minuciosamente. Unos han resultado ser más sencillos en cuanto a la composición de los mismos, ya que constan de una captación de agua - fuente o noria de sangre-, alberca para la acumulación y la regulación del débito, acequia principal, de la que se derivan otras secundarias, y bancales regados, construidos en forma de terraza, que se adaptan a los fondos o a las laderas de los valles, transformándolos artificialmente. Otros, como El Molinell y el Riu de Montlleó, representan sistemas hidráulicos más complejos, donde se combinan terrazas irrigadas y molinos harineros, junto con otros elementos - azudes, acequias y balsas - que hacen posible su organización y funcionamiento.

En todos los casos, los sistemas hidráulicos están relacionados con áreas de residencia de datación andalusí, localizadas con precisión a través de los restos arqueológicos hallados y, en algunas ocasiones, como en El Molinell y en el Riu de Montlleó, documentadas inmediatamente después de la conquista feudal. Estas áreas siempre se encuentran situadas por encima de la línea de rigidez o acequia principal, de modo que su presencia no dificulta ni el desarrollo ni el funcionamiento normal del sistema.

Además, las excavaciones realizadas en las zonas residenciales de dos de los asentamientos investigados - Foies-La Cassasa y L'Arranc- han facilitado abundante información sobre las formas de las viviendas, las técnicas constructivas empleadas y la estratigrafía y datación del material cerámico encontrado, que abarca el período comprendido entre los siglos $\mathrm{x}$ al Xw. Asimismo, esta parte de la investigación ha proporcionado una infor-

${ }^{64}$ Poveda (1987), pp. 210-211. 
mación más ajustada sobre cuál era el perímetro residencial del asentamiento y, en el caso de Foies, su posterior reutilización por los colonos cristianos.

El estudio de estos asentamientos parece confirmar que la estructura esencial del espacio hidráulico es el resultado de un diseño previo, en el que se articulan los distintos elementos que forman parte del sistema, a partir de la exigencia de la gravedad como hecho fundacional de toda hidráulica. De igual modo, la rigidez de estos espacios y su limitación han hecho posible reconocer con suficiente nitidez la estructura original, pudiendo distinguir también las posibles ampliaciones o adiciones al diseño primitivo.

En el hisn de Culla los espacios regados son pequeños ya que, habitualmente, son inferiores a media hectárea. Sólo en el Riu de Montlleó se sobrepasa la hectárea de bancales regados y, en el municipio de Benassal, el conjunto de parcelas de su entorno se aproxima a las dos hectáreas.

Por último, debo señalar que además de la agricultura irrigada, el trabajo realizado hasta ahora parece desvelar que en el Castell de Culla la obtención y transformación del mineral de hierro, junto con la dedicación ganadera, debieron ser otras formas de lograr recursos económicos practicadas por aquellas comunidades campesinas, tanto para el consumo interno como, seguramente, para el intercambio. Una investigación específica sobre estas actividades podría deparar resultados relevantes.

\section{BIBLIOGRAFÍA}

ACIÉN, M. (1984a): «La formación y destrucción de al-Ándalus», en M. Barceló (dir.): Historia de los Pueblos de España, Barcelona, Argos Vergara, vol. I, pp. 21-45.

- (1984b): «De la conquista musulmana a la época nazari», en Málaga, Historia, Granada, vol. II, pp. 469-510.

- (1989): «Poblamiento y fortificaciones en el sur de al-Ándalus. La formación de un país de busun», III Congreso de Arqueología Medieval Española, Oviedo, vol. I, pp. 137-150.

Aguilera, A., y Fabregat, C. (1994): «Primera aproximació al catàleg florístic de Culla», en Imatge de Culla. Estudis recollits en el 750é aniversari de la Carta de Població (1244-1994), Culla (Castellón), Comissió de Cultura de Culla per al 750 Aniversari de la Carta de Població, vol. I, pp. 117-157.

AL-IDRISI (1989): Los caminos de al-Ándalus en el siglo XII, estudio, edición, traducción y anotaciones por J. Abid Mizal, Madrid, CSIC.

ARGEMI, M. (1996): «El sistema de molinos andalusi del guz de Yartan (Mayurqa)», Agricultura y regadio en al-Ándalus. Il Coloquio de Historia y Medio Físico, Almería, pp. 259-271. 
- et al. (1995): «Glosario de términos hidráulicos», en El agua en la agricultura de al-Andalus, Granada, El Legado Andalusí-Lunwerg Editores, pp. 163-189.

- et al. (1997): «Un sistema hidràulic compartir per diversos assentaments: La Vall de Buscastell», en M. BARCELó (coord.): El curs de les aigües. Treballs sobre els pagesos de Yabisa (290-633 H/ 902-1235 d. C.), Ibiza, Quaderns d'Arqueologia Pititusa, 3, Consell Insular d'Eivissa i Formentera, pp. 37-51.

BARCミLÓ, C. (1994): «Una làpida amb inscripció trobada al terme municipal de Culla», Imatge de Culla. Estudis recollits en el 750é aniversari de la Carta de Població (1244-1994), Culla (Castellón), Comissió de Cultura de Culla per al 750 Aniversari de la Carta de Població, vol. I, pp. 209-216.

BARCELÓ, M. (1984-1985): «Un estudio sobre la estructura fiscal y procedimientos contables del Emirato Omeya de Córdoba (138-300/755-912) y del Califato (300-366/912-976)», Acta Mediaevalia, 5-6, pp. 45-72.

- (1988): «La arqueología extensiva y el estudio de la creación del espacio rural», en M. BARCEló et al.: Arqueología Medieval. En las afueras del "medievalismo», Barcelona, Crítica, pp. 195-274.

- (1989): «El diseño de espacios irrigados en al-Ándalus: un enunciado de principios generales», El agua en zonas áridas: Arqueologia e Historia. I Coloquio de Historia y Medio Físico, Almería, vol. I, pp. XV-XIXI.

- (1992a): «Historia y Arqueologia», Al-Qantara, XIII, pp. 457-462.

- (1992b): «Quina arqueologia per al-Andalus?», Coloquio Hispano-Italiano de Arqueologia Medieval, Granada, pp. 243-252.

- (1992c): «¿Por qué los historiadores académicos prefieren hablar de islamización en vez de hablar de campesinos?», Arqueologia Medievale, XIX, pp. 63.73.

- (1992d): «Rodes que giren dins el foc de l'infern o per a què servia la moneda dels taifes?», Rubartayr, 0 (= Gaceta Numismática, 105-106), pp. 15-23.

- (1995): «De la congruencia y la homogeneidad de los espacios hidráulicos en al-Ándalus», en El agua en la agricultura de al-Ándalus, Granada, El Legado Andalusi-Lunwerg Editores, pp. 25-38.

- (1996): «La cuestión del hidraulismo andalusi», en El agua que no duerme, Granada, El Legado Andalusí, pp. 13-47.

- (coord.) (1997): El curs de les aigües. Treballs sobre els pagesos de Yabisa (290-633 H/ 902-1235 d. C.), Ibiza, Quaderns d'Arqueologia Pitiusa, 3, Consell Insular d'Eivissa i Formentera.

- y KrRCHNER, H. (1995): Terra de Falanis. Felanitx quan no bo era. Assentaments andalusins al territori de Felanitx, Palma de Mallorca, Ayuntamiento de Felanitx-Universidad de las Islas Baleares.

- et al. (1988): Arqueologia medieval. En las afueras del «medievalismo», Barcelona, Crítica.

- et al. (1995): «Buscastell, un sistema hidráulico andalusí en Ibiza: lo viejo y lo nuevo» $10^{\circ}$ Congresso de Arqueologia Peninsular. Actas VI, Oporto, pp. $455-463$.

- et al. (en prensa): The design of bidraulic system in al-Ándalus. The cases of Guajar Faragüit (Los Guajares, Granada, Spain) and Castellitx, Aubenya and Biniatró (The Balearic Island) VII H/ XIII Cent. A. D., Bellaterra (Barcelona), Universidad Autónoma de Barcelona. 
Bazzana, A.; Cressier, P., y Guichard, P. (1988): Les châteaux ruraux d'al-Ándalus, Madrid, Publications de la Casa de Velázquez.

CARBOnero, M. A. (1986): «Els molins hidràulics de l'illa de Mallorca», en Quinze anys de premis d'investigació Ciutat de Palma, Palma de Mallorca, Ayuntamiento de Palma de Mallorca, pp. 137-155.

- (1992): L'espai de l'aigua. Petita hidràulica tradicional a Mallorca, Palma de Mallorca, Consell Insular de Mallorca.

De Terán, M., y Solé Sabaris, L. (dirs.) (1969): Geografía Regional de España, Barcelona, Ariel.

FERNÁNDEZ, S. (1982): «El molino hidráulico medieval en la provincia de Málaga», Acta Historica et Archeologica Medievalia, 3, pp. 208-238.

Fontanals, R. (1984): Un plànol de la Sèquia de la Vila del segle XIV (Ciutat de Mallorca), Palma de Mallorca, Ayuntamiento de Palma de Mallorca.

FORCADA, V. (1990): «El Castell de Culla: sus términos generales», Boletín de la Sociedad Castellonense de Cultura, LXVI, pp. 3-34.

- (1994): «El Castell de Culla: territorialitat i estructura», Imatge de Culla. Estudis recollits en el 750é aniversari de la Carta de Població (1244-1994), Culla (Castellón), Comissió de Cultura de Culla per al 750 Aniversari de la Carta de Població, vol. I, pp. 225-248.

Furió, A., y Martinez Sanmartin, L. P. (1994): «Assuts i molins sobre el Xúquer en la Baixa Edat Mitjana», IV Congrés d'Arqueologia Medieval Espanyola. Societats en Transició, Alicante, vol. III, pp. 578-586.

González, A., y PovedA, A. (en prensa): Asentamientos y sistemas bidráulicos andalusies en el territorio del Castell de Culla (Alto Maestrazgo, Castellón), Alicante.

GREGORI, J., et al. (1985): Temes d'etnografia valenciana, vol. III, Valencia.

GUICHARD, P. (1976): Al-Ándalus. Estructura antropológica de una sociedad islámica en occidente, Barcelona, Barral Editores.

Guinot, E. (1986): Feudalismo en expansión en el norte valenciano. Antecedentes y desarrollo del señorio de la Orden de Montesa. Siglos XIII y XIV, Castellón, Diputación Provincial de Castellón.

- (1994): «Introducció al procés d'ocupació de l'espai i a les cartes de poblament a l'Alt Maestrat de Castelló en el segle XII», en Imatge de Culla. Estudis Recollits en el 750é aniversari de la Carta de Població (1244-1994), Culla (Castellón), Comissió de Cultura de Culla per al 750 Aniversari de la Carta de Població, vol. I, pp. 17-36.

IBN AL-ABBAR (1887): Kitab al-Takmila li-Kitab al-Sila, editado por F. Codera, Madrid, Biblioteca Arábico-Hispana, V-VI.

- (1956): Al-Takmila al-Sila, editado por 'Izzat al-'Attar al-Husayni, 2 vols., El Cairo-Bagdad.

KIRCHNER, H. (1994a): «Espais irrigats $i$ assentaments andalusins a la Vall de Bunyola (Mallorca)», IV Congrés d'Arqueologia Medieval Espanyola. Societats en Transició, Alicante, vol. II, pp. 517-523.

- (1994b): «Espais irrigats andalusins a la Serra de Tramuntana de Mallorca i la seva vinculació amb el poblament», Afers, IX-18, pp. 313-336.

- (1995a): «Construir el agua. Irrigación y trabajo campesino en la Edad Media», Arbor, CLI, 593, pp. 36-64. 
- (1995b): «Espacios irrigados de origen andalusí en la Sierra de Tramuntana de Mallorca. El caso de Coanegra», 1. ${ }^{\circ}$ Congresso de Arqueologia Peninsular. Actas VI, Oporto, pp. 351-359.

- (1996): «Colonització de Lo Regne de Mallorques qui és dins la mar. La subversió feudal dels espais agraris andalusins a Mallorca», en P. SÉNAC (comp.): Histoire et Archeologie des Terres Catalanes au Moyen Age, Perpiñán, Presses Universitaires de Perpignan, pp. 279-316.

- (1997): La construcció de l'espai pagès a Mayurqa: les valls de Bunyola, Orient, Coanegra i Alaró, Palma de Mallorca, Universitat de les Illes Balears.

- (en prensa): «Los Bani Furanik en las Islas Orientales de al-Ándalus», en A. MalpiCa (coord.): De la sociedad islámica a la feudal. Veinte años de al-Andalus. Homenaje a Pierre Guichard, Granada.

- y NAVARRO, C. (1993): «Objetivos, métodos y práctica de la arqueología hidráulica», Archeologia Medievale, XX, pp. 121-150.

- et al. (1986): «Molins d'origen musulmà a Banyalbufar», Estudis Baleàrics, 21, pp. 77-86.

Miralles, J. (1983): «El Castell de Culla», Boletin de la Sociedad Castellonense de Cultura, LIX, pp. 237-241.

NAvARRO, C. (1989): «Prospección arqueológica del asentamiento andalusí de Tobarra (Albacete). I. El molino de Polope: un molino musulmán en activo», Revista de Estudios Tobarreños, 1, pp. 97-110.

- (1995): «El ma'gil de Liétor (Albacete): un sistema de terrazas irrigadas de origen andalusí en funcionamiento», $1 .^{\circ}$ Congresso de Arqueologia Peninsular. Actas VI, Oporto, pp. 365-378.

- (1996): «El tamaño de los sistemas hidráulicos de origen andalusí: la documentación escrita y la arqueología hidráulica», II Coloquio de Historia y Medio Físico. Agricultura y regadio en al-Ándalus, Almería, pp. 177-189.

PovedA, A. (1987): Toponimia àrabo-berber $i$ espai social a les Illes Orientals d'al-Ándalus, Bellaterra (Barcelona), Edición Microfotográfica, Universitat Autònoma de Barcelona.

- (1992): «Mayurqa, un espacio agrario de alquerías y rahales», Estudis d'Història Econòmica, 1, pp. 5-11.

- (1995): «Tipus d'explotacions agràries i models d'assentaments a les Illes Orientals d'al-Ándalus (Illes Balears), segons la toponímia àrab i berber», en V. M. Rosselló y E. Casanova: Materials de Toponimia. Estudis de Toponimia Valenciana, Valencia, Universitat de València-Generalitat Valenciana, vol. II, pp. 1061-1067.

- (1997): «Estudio de dos casos de hidraulismo andalusí localizados en el Alto Maestrazgo (Castellón)», Áreas. Revista de Ciencias Sociales, 17, pp. 13-29.

- (en prensa): «Asentamientos rurales y toponimia en las Islas Orientales de al-Ándalus», en A. MALPICA (coord.): De la sociedad islámica a la feudal. Veinte años de al-Andalus. Homenaje a Pierre Guichard, Granada.

RIERA, M. M., y SoberaTs, N. (1992): «Introducció a l'estudi del sistema hidràulic d'Alaró (Mallorca)», Bolletí de la Societat Arqueològica Lul-liana, 47, pp. 61-73.

SANFelí, T.; Box, A., y JoRDán, M. M., (1994): «Perfil geològic i ambiental de Culla», en Imatge de Culla. Estudis recollits en el 750é aniversari de la Carta 
de Població (1244-1994), Culla (Castellón), Comissió de Cultura de Culla per al 750 Aniversari de la Carta de Població, vol. I, pp. 169-194.

SELmA, S. (1989): «La integración de los molinos en un sistema hidráulico: la alquería de Artana (Serra d'Espadà, Castelló)», I Coloquio de Historia y Medio Físico. Arqueología e Historia, Almería, vol. II, pp. 713-736.

- (1991): «El molí hidràulic de farina i l'organització de l'espai rural andalusí. Dos exemples d'estudi arqueològic espaial a la Serra d'Espadà (Castelló)», Melanges de la Casa de Velázquez, XXVII, pp. 65-100.

- (1993): Els molins d'aigua mediavals a sharq al-Ándalus, Onda, Ajuntament d'Onda.

VARIOS AUTOREs (1987): Atlas hidrogeológico de la provincia de Castellón, Castellón, Diputación Provincial de Castellón.

- (1990): Guía de la naturaleza de la Comunidad Valenciana, Valencia, Editorial Prensa Alicantina-Institución Valenciana de Estudios e Investigación.

- (1991): Atlas temático. Comunidad Valenciana, Alicante, Editorial Prensa Alicantina.

VEA, L. (1996): «Los gelida: segmentación clánica beréber y producción de espacios rurales hidráulicos en al-Andalus. Primera aproximación: los riegos de Margarida (Planes de la Baronía, Alacant)», Agricultura y regadio en al-Ándalus. II Coloquio de Historia y Medio Físico, Almería, pp. 203-213.

Watson, A. M. (1983): Agricultural Innovation in the Early Islamic World, Cambridge, Cambridge University Press. 